\title{
Wellness Brand in Personal Internet-blogs and Social Networks
}

\author{
Irina $G$. Sidorova ${ }^{1, *}$ \\ ${ }^{1}$ Volgograd State Medical University, 1, Pavshikh Bortsov Sq., 400131, Volgograd, Russia
}

\begin{abstract}
The article deals with the brand of 'wellness' on the basis of hypertexts of personal Internet communication. The author focuses on wellness-concept branding in Russian and English texts of personal blogs and social networks. The author has concluded that the hypertextual medium of personal Internet discourse is an efficient genre platform to influence the targeted audience, to make a search for wellness followers, having simple, convenient and necessary tools to promote the healthy life style, to increase the number of clients of health centres, spa and fitness centres and wellness-industry, in general.
\end{abstract}

\section{Introduction}

An ordinary person's style of life is examined more and more often by researchers of different scientific spheres: medicine, sociology, education, economics, philology and linguistics, of course [1]. In the era of computerization, artificial intelligence and global domination of gadgets the issues of health and well-being acquire new relevance. Searching for answers to these problems people tend to access the Internet and try to find the needed answers; this phenomenon is fully understandable in light of unavoidable processes of medicalization of the Internet communication in the World Wide Web. This process is understood as one which may be explained by the broad influence of medicine on the Internet-mediated communication, which in its turn changes the thinking style and language of participants, generating new rules, conventions and formats of the medical Internet discourse [2].

Speaking about the significance of Internet communication tone should evaluate the purposes with which an Internet-user joins the on-line communication. It is obvious that the commonest questions to be asked in the Internet-societies are questions associated with health, beauty and good diet, in other words, questions about healthy life style and wellness.

\section{Background}

The principles of wellness as principles of healthy life style including the components of physical and mental exercise, a rich balanced diet, periods of relaxation and spiritual harmony as well as beauty and care for the face and body, were first introduced by an American doctor, Halbert L. Dunn in 1959. He described the essentials in his study "High-level Wellness: A Collection of Twentynine Short Talks on Different Aspects of the Theme" in 1961 [3]. From that time this term has been applied to a systematic theoretical and practical approach to achieving well-being [4] The researchers of the sphere of medical and social practice claim that the semantic meaning of 'wellness' includes 6 characteristics interacting with one other: the physical, social, psychological, intellectual, emotional and spiritual component. Based on the results of a study conducted by Malyarenko et al. we attempt to provide definitions of meaningful characteristics of each aspect of wellness-theory [4]:

1) physical component: this characteristic implies an individual's understanding of his own physical state and a positive effort to improve it;

2) social characteristic is an indication that one has a social environment: a family and a friend, or friends;

3) psychologic characteristic comprises the analyses of positive effort aimed to change the circumstances of one's life;

4) emotional constituent implies the ability to have a strong feeling of self-identification and a positive feeling of self-respect;

5) spiritual component is the positive feeling that one's life is meaningful;

6) intellectual characteristic assumes implies a person has the feeling of endogenous energization by the corresponding intellectual activity.

According to researcher Malarenko et al., we suppose that all of these 6 characteristics of the wellness-system are interrelated, and disturbance of one of them will certainly result in disturbance of the system in general. Clinical trials performed by Malarenko et al. demonstrate that the capacity of the term 'wellness' is greater than the meaning of health. The wellness-system connects the spiritual and material, the past, present and future of an individual; the complex approach of this system involves an ability to make an adequate evaluation of one's health and one's relation to oneself and one's life [4], which undoubtedly should yield effective and positive results. That is why we consider supposing the brand of healthy lifestyle is a way of using all human resources effectively

\footnotetext{
* Corresponding author: ira.sidorovafomicheva@gmail.com
} 
to achieve harmony not only with your own body (promoting health and stamina) but with the society (favourable climate in the family and on the job).

\section{Analysis of Wellness Brand}

In the present study we analyzed the hypertexts of personal Internet-blogs and profiles of social networks in Russian and English, in which bloggers and authors of personal profiles of networks publicize their views on wellness brand. We also looked by which linguistic means they affect the targeted audience of followers, which will be necessary for branding and rebranding of web sites of health centres, spa and fitness centres.

Personal Internet communication is considered to be a specific format of interpersonal verbal and non-verbal interaction with particular register of communication where Internet-users can create their own and unique virtual world in which all criteria of communication are established only by the author while others may accept his position or not. Upon that we should mention that the genre stratification of the personal Internet discourse is determined by types of explicated communicative acts of the Internet-users as well as technological peculiarities of networking platforms [5]. Impetuous development of the latter has surely given a powerful impulse to emergence and dynamic updating of networking technologies of blogging and twitting.

Modern society inspired by ideas of wellness-concept cannot help responding to the development of its aspects: the business medium takes profit from sales and services oriented at healthy diet, prolongation of youth, keeping fit, effective treatment of not only bodily suffering but also emotional issues with relaxation techniques of spa and yoga centres. Some social networks become the base for promoting the product and service lines of wellnessindustry. For example, YouTube channel is used by famous bloggers to personal video blogs, the Instagram is used by Internet-users to follow friends, celebrities and other famous people's lives [6], and otherwise they begin to read the Internet-content supplied with hashtags of good diet (\#instafood \#instagramanet \#instatag \#food \#foodporn \#foodie \#foodgasm \#foodpics \#foodpic \#foodstagram \#foods \#foodphotography), of fitness and health condition (\#fitnessgoals, \#fitness, \#fitnessmotivation), and of course using the hashtags of wellness (\#wellness, \#krasota, \#wellnesskids, \#spa and etc.).

According to the meanings of 'brand' as a trade mark combined with emotional and evaluative stereotypes of the current product [7], 'branding' is a complex of procedures to create the brand of the product [8], while 'rebranding' is a process of changing the existing brand to improve its influence on potential clients. In our study we understand 'brand wellness' as a complex of knowledge and techniques oriented at promotion of a person's healthy life style and achieving the highest harmony level of physical, social, spiritual, mental, emotional and intellectual constituents of wellness-system. It is obvious that such understanding of wellness-system and wellnesstechnologies may be easily incorporated in the logic of institutional communicative practices combined with the author's personalization in describing available content in the Internet space [9].

Thus, a famous English blog 'The Real Food Dietitians' [10] created by registered dietitian nutritionists Stacie Hassing and Jessica Beacom is a vivid example of branding healthy life style. The logo of this Internet blog is 'EAT WELL. LIVE WELL. BE WELL' which expresses the bloggers' concept - if you eat healthy, you will live well and you will be healthy. The strategic principles of attracting Internet-users are written in the description to the blog: "They've combined their love of nutrition, health and real food with the concepts of ease and convenience to bring you recipes that are big on flavor but short on ingredients" [10].

Stacie and Jessica's posts are a list of recipes and recommendations about healthy diet. For example, the post 'Confused about what to eat? Welcome to Real Food 101 where we'll be your guides in all things eating' is a conversation with Internet-users who are designated as 'eaters' by the authors. In the texts there are practically no technical terms, but they have words and sentences with the meaning of illocution: "We're going to dive right into the heavy hitters of the nutrition", "We'll talk about how to choose quality meats, seafood, and dairy", "how to include snacks, treats, and alcohol as part of an overall healthy lifestyle", "We'll talk about organic - what that means, which foods are worth the extra cost, the farreaching benefits of organic agriculture", and so on.

Thus, the important distinctive feature of the personal Internet communication in personal blogs is the Internetusers' reaction, which is a demonstrative example in case of the blog under discussion. The Internet-user JASMIN placed the following comment to the post [10]: "I am a busy, working mother of two little boys ages 5 and 10 months. I am nursing the 10-month old. I am struggling to achieve my optimum health and energy through food. I am especially interested in how to incorporate treats and snacks into a healthy and balanced diet. Thank you!" Words of thanks for the bloggers are mixed with description of daily routine activities determine the importance of communication on this theme - the theme of healthy diet and the target audience.

Internet-blogs about physical exercise, about how to make your body beautiful and to keep this effect are also of great interest. Thus, the blog 'MyFitnessPal' can be considered a place of blog-posts on different themes, for example, nutrition, weight loss, fitness, inspiration and so on [11] where the bloggers explain in some detail the new rules of healthy habits and diet, and the principles of being-well and wellness, in general. A heading 'inspiration' is of interest for the present study; it real life stories of success from those who struggle with overweight, sedentary style, whose lives and habits have changed when they began to follow the recommendations of the blog 'MyFitnessPal'. And it is worth mentioning the story of beautiful Jenni Buckingam who finished her post with these words: "My advice to other people is not to give up hope. $<\ldots>$ When I was heavy, Ifelt so hopeless in my body. I would look at weight-loss photos on Instagram and think I'd never be able to do that. It felt unattainable. But consistency is the secret to all of it. Just 
keep going, and if you mess up, get right back to your plan. Progress will come”. The narrative nature of this post draws closer the author and the Internet-users, making their communication open and honest. The appeal follows one's program rigorously so as to achieve the beautiful and healthy body ending a convincing statement "Progress will come" makes emphasizes the effect of friendly interpersonal communication in the Internet.

The issues associated with the scope of physical exercise, its regimen and techniques are described in detail by blogger Lauren Bedosky, a freelance fitness writer, who specializes in covering running and strength training topics. In her post 'How many workouts can you miss without losing progress?' she tells about possibilities of missing some workouts and possible 'effects'. The author's approach to get the readers interested is noteworthy as she first mentions the theme, then she gives some explanations, and at the end she writes the appeal 'Read on to find out' after reading which you should want to read it to the very ending: "At some point, everyone misses a workout (or two). It isn't a matter of ifbut when. From injury to illness to vacation and work stress, there are plenty of reasons you might miss a workout. But how many workouts can you skip before you start losing your hard-earned gains? Read on to find out".

Besides traditional genres of blogging it is a good idea to mention video blogs which are starting to become popular in promoting wellness brand. Thus, Irina Basuk, a top leader the Russian branch of Oriflame company, is a famous representative of wellness industry in the country. The image of a successful lady is realized in several genre formats of personal Internet communication: personal Internet-blog on the You-Tube platform about beauty, make-up, and face care with the latest reviews of all products of the company, all of them accompanied with her personal advice how to promote business in social networks [12], personal profile on Instagram platform [13] with photos not only of her business but her family, her life and travelling, personal profile in Russian social network 'ВКонтакте' ('In the contact') with photos and video stories about her personal success [14], personal profiles in Russian social networks 'Одноклассники' ('Classmates') [15] and Facebook [16] with a collection of photo and video-fragments of her success stories, a blog in micro-blog Twitter [17], as well as her official web-page of Irina Basuk's personal Internet-site [18]. The presentation of Irina Basuk personality in the mentioned genres of the personal Internet discourse is shaped by her communicative acts in the Internet, realized by rational, value oriented, traditional, affective and personality marked communicative acts [19]. Here we understand the hypertexts of genres of the personal Interne discourse as a manner of connecting the meaningful structure, the composition of internal links of contents, technical medium and linguistic means corresponding to the author's pragmatics.

Considering that social networks gives the holders' profiles a complete communicative frame structure for self-presentation of the linguistic personality. The choice of linguistic means becomes the determinant in attracting the Internet-followers. The texts express the emotional state of the author by using a set of linguistic means which emphasize the meaning and the expressive attitude to the theme under discussion, and a large amount of simple exclamatory sentences are easily understood by the readers. Below we cite a portion of a post of 01.05.2019 [14]:

1 мая, очередной день рождения. Год назад в коние апреля на горе на Фудзияма (Япония) загадала желание встретить день рождения в горах! И вспомнила только тогда, когда стала подниматься на подъемнике !!!! Да! Я вспомнила этот кайф и восторг! А ещё я ревела в Австралии, когда увидела каньон как в фильмах, от которых дух захватывает

May $1^{\text {st }}$, another birthday. A year ago in the end of April on Mount Fuji (Japan) I made a wish to see my birthday in the mountains! And I remembered it only when I began the rise in the elevator!!! Yes!! I remembered this kaif and delight! An also I howled in Australia when I saw the canyon like in the movies which make me choke with emotion.

The example above shows that the personal Internet discourse uses the conversational style whose aim is reducing the distance from the readers to the format 'here and now'. In the syntaxes there are many exclamatory sentences with repetitions and comparisons as well as also emoticons and smiles and other iconics. However, the number of such examples comprise approximately one third of the total amount: to a considerable degree, information of advertising nature is predominant in the posts: “Обзор моих покупок по 6 каталогу Орифлейм 2018" (Review of my purchases from catalog N.6 Oriflame 2018); "Ищите бюджетные аналоги люкса? - Запечные тени Giordani Gold аналог хайлайтера HUDA Beauty" (Are you seeking for low cost analogs of luxury products? - Baked eye shadow Giordani Gold, analog of HUDA Beauty highlighter"); "Mou незаменимые продукты по уходу за волосами” (Му essential products for hair care)); and so on. It is obvious that the advertising style with specific verbal and nonverbal means in social networks fits perfectly the aim of wellness branding.

If we mention twitting in wellness branding, we should say that this micro-blog can be used only as an index to the Internet-content which is placed in different social networks.

\section{Conclusion}

Thus, the current study of the hypertexts of genres of the personal Internet discourse shows that wellness brand representing a complex of knowledge and techniques oriented at promoting healthy life style and achieving the highest harmony level of physical, social, spiritual, mental, emotional and intellectual constituents of wellness-system can be considered as a way of branding and rebranding of healthy life style and the services of its realization. Moreover, the hypertextual medium of the personal Internet discourse is an effective genre platform for realization of personal aims, searching for wellness- 
followers with the ready-to-use tools for placing the content to attract the interest to the wellness industry.

\section{References}

1. J. Wu, M. Walker, P. Anand and S. Whittaker, Linguistic Reflexes of Well-Being and Happiness in Echo, Proceedings of the 8th Workshop on Computational Approaches to Subjectivity, Sentiment and Social Media Analysis, 81-91 (2017)

2. I. G. Sidorova, Medicalization of the Internet Discourse: Communicative and pragmatic characteristics of a Personal Doctor's Web-site, Scientific J. "Homo Loquens (The Issues of Linguistics and Translatology)" 10 186-198 (2017)

3. H. L. Dunn, High-level Wellness: A Collection of Twenty-nine Short Talks on Different Aspects of the Theme (Mt. Vernon Printing Company, Washington, DC, 1961)

4. T. N. Malarenko, A. T. Bykov, V. P. Terentyev, S. V. Papchenko, Yu. Ye. Malarenko, From the Biomedical to Sociomedical View of the Matter of Health, Scientific J. "Medical Herald of the South of Russia" 4, 12-23 (2011)

5. V. A. Mityagina, I. G. Sidorova, Genres of the Personal Internet Discourse: Communicative Explications of a Personality, Scientific J. "Speech Genres" 2, 105-115 (2016), URL. DOI: 10.18500/2311-0740-2016-2-14-105-115

6. Yu. V. Schurina, Genre Diversity of the Social Network 'Instagram', Scientific J. "Speech Genres" 1 156-168 (2016) URL. DOI: 10.18500/2311-07402016-1-13-1

7. V. I. Karasik, Language matrix of culture (Paradigma Publ., Volgograd, 2012)
8. V. A. Mityagina, I. G. Sidorova, "Brand Slogan of a Region: Valuable Aspect of Place Marketing”, SHS Web of Conferences 50, 01112 (2018) CILDIAH2018. Retrieved from: https://doi.org/10.1051/shsconf/20185001112

9. A. Taff, M. Chee, J. Hall, M. Y. Dulitseen Hall, K. N. Martin, A. Johnston, Indigenous Language Use Impacts Wellness (The Oxford Handbook of Endangered Languages, 2018)

10. English blog “The Real Food Dietitians”, Retrieved from:. https://therealfoodrds.com/

11. English blog "MyFitnessPal", Retrieved from: https://blog.myfitnesspal.com/

12. YouTube Channel of Irina Basuk, Retrieved from:. https://www.youtube.com/channel/UCw9YZJ7EaL HEYJlc6yWGnVQ

13. Instagram Profile of Irina Basuk, Retrieved from https:/www.instagram.com/irinabasyuk/?hl=ru

14. Social Network 'In the contact' Profile of Irina Basuk, Retrieved from: https://vk.com/orioffice

15. Social Network 'Classmates' Profile of Irina Basuk, Retrieved from: https://ok.ru/irina.basyuk

16. Social Network 'Facebook' Profile of Irina Basuk, Retrieved from: https://www.facebook.com/irina.basuk

17. Micro-blog Twitter Profile of Irina Basuk, Retrieved from: https://twitter.com/irinabasyuk

18. Personal Web-site of Irina Basuk, Retrieved from: http://orioffice.ru/istoriya uspeha basyuk iriny2

19. I. G. Sidorova, Communicative and Pragmatic Characteristics of Genres of the Personal Internet Discourse (Web-site, Internet-blog, Social network and Comment) (Published thesis of a Candidate of Philology, Volgograd, 2014) 